\title{
Small-scale friction welding of similar and dissimilar stainless steels*
}

\author{
by FUKUMOTO Shinji**, KATAYAMA Koki***, OKITA Kozo ${ }^{* * * *}$, TOMITA Tomoki***** and YAMAMOTO Atsushi******
}

Friction welding was carried out on austenitic and ferritic stainless steels (diameter: $3 \mathrm{~mm}$ ). The practical process windows, that is, weld lobes, were shown for similar and dissimilar welding. Proper balance of heat and deformation was necessary to form a favorable weld interface that had no unbonded regions and oxide layers. The microstructural refinement of both stainless steels occurred near the weld interface because of dynamic recrystallization. In the case of dissimilar welding, a lamellar structure of alpha and gamma phases was formed in the microstructural refinement region of type 430 steel, and strain-induced martensite was formed in type 304 steel.

Key Words: friction welding, small-scale, stainless steels, dissimilar joint, microstructure, weld lobe

\section{Introduction}

It is well known that fusion welding of stainless steels has some problems. In the case of fusion welding of ferritic stainless steels, large grains are expected in the heat-affected zone (HAZ) close to the weld metal; the formation of these grains leads to the poor strength of the steels. Further, the weldability of austenitic stainless steels is better than that of the ferritic stainless steels; nevertheless, the sensitization in HAZ and formation of deltaferrite in the weld must be paid attention to ${ }^{1,2)}$. In the case of dissimilar welding of ferritic and austenitic stainless steels, fusion processes seem to be unfavorable. It has been reported that dissimilar stainless steels joints were successfully made by using friction welding ${ }^{3-5)}$. Thus far, a combination of austenitic and ferritic stainless steels has been mainly used in $\mathrm{TiCl}_{4}$ reduction retorts because the austenitic steels exhibit superior mechanical properties and oxidation resistance at elevated temperatures and ferritic steels can avoid the problem of nickel leaching by molten magnesium ${ }^{3}$. Moreover, the dissimilar welding of ferritic and austenitic stainless steels should be noted in terms of their magnetic property. A magnetic iron core in a small displacement sensor can be joined to nonmagnetic metals by using a screw cramp, an adhesion bond, or silver brazing. Nowadays, friction welding is required to make small and reliable magneticnonmagnetic dissimilar stainless steel joints.

In contrast to the extensive work done on regular or largescale friction welding as used in automotive and appliance industries for making parts with a round bar diameter larger than approximately $10 \mathrm{~mm}$, no systematic investigations have been carried out on small-scale friction welding. The heat input of friction welding strongly depends on the diameter of samples and

\footnotetext{
*Received: 2008. 11. 18

**Member, Graduate school of Engineering University of Hyogo

*** Undergraduate student, University of Hyogo

***** Osaka Sangyo University

******Member, Hyogo Prefectural Institute of Technology

$* * * * * *$ Graduate school of Engineering University of Hyogo
}

increases with an increase in the diameter because of the nature of the process ${ }^{6}$. Assuming the friction coefficient is constant during the welding, the total energy for welding $(W)$ is expressed as,

$$
W=\mathrm{A} p f N r^{3}
$$

where $\mathrm{A}$ is the constant, $p$ is the pressure, $f$ is the friction coefficient, $N$ is the rotation speed and $r$ is the radius of specimen $^{7}$. For example, in order to reduce the radius of specimens by a factor of 2 , the rotation speed should be increased by a factor of 8 . Additionally, the axial pressure, which is another major parameter that affects the heat generation at the faying interface, cannot be increased significantly in the case of smallscale friction welding since the sample may buckle easily.

The objective of this study is to investigate the feasibility of similar and dissimilar friction welding of ferritic and austenitic stainless steels having a small diameter. The microstructural development of the joint and the practical process window were also investigated.

\section{Experimental procedures}

Round bars (diameter: $3.0 \mathrm{~mm}$ ) of type 304 and type 430 stainless steels were used in this study. The chemical compositions are given in Table 1. The tensile strengths of type 304 and 430 stainless steels are $920 \mathrm{MPa}$ and $655 \mathrm{MPa}$, respectively. The faying surfaces were flattened by a lathe and cleaned with acetone immediately before welding. A continuous drive friction welding machine (FF-002III-N by Nitto Seiki Co. Ltd.) was used for conducting the welding trials. A major difficulty in the optimization of the friction welding parameters was the large number of variables involved. The effects of rotation speed $(N)$, friction time $\left(t_{1}\right)$, and forging pressure $\left(P_{2}\right)$, which were generally accepted as the variables controlling the joint quality in friction welding ${ }^{8)}$, were investigated. The rotation

\begin{tabular}{ccccccccc} 
Table 1 & \multicolumn{7}{l}{ Chemical compositions of stainless steels. (mass\%) } \\
\hline Type & $\mathrm{C}$ & $\mathrm{Si}$ & $\mathrm{Mn}$ & $\mathrm{P}$ & $\mathrm{S}$ & $\mathrm{Ni}$ & $\mathrm{Cr}$ & $\mathrm{Fe}$ \\
\hline 304 & 0.03 & 0.3 & 1.53 & 0.034 & 0.008 & 9.15 & 18.65 & Bal. \\
\hline 430 & 0.03 & 0.37 & 0.42 & 0.022 & 0.003 & 0.17 & 16.02 & Bal. \\
\hline
\end{tabular}


speed and the friction time were varied from 1500 to $10000 \mathrm{rpm}$ and 0.1 to $2.5 \mathrm{~s}$, respectively. Forging pressures of 150 and 300 MPa were used. Further, the friction pressure and the forged time were maintained constant at $70 \mathrm{MPa}$ and $6.0 \mathrm{~s}$, respectively, throughout the study.

Tensile and bending tests were carried out in order to evaluate the mechanical properties of the joints. The shape of the tensile test specimen is shown in Fig. 1. The tensile tests were performed at room temperature using an Instron type testing machine with a crosshead speed of $1.67 \times 10^{-2} \mathrm{~mm} \mathrm{~s}^{-1}$. The bending tests were carried out using the following simple method: one end of the specimen was fixed by a jig, and the other end was loaded and bent. The purpose of the bending test was not to quantitatively but to qualitatively evaluate the joint strength. The cross sections of the joints were observed by using an optical microscope. The microstructures of the weld interface were investigated by using a scanning electron microscope (SEM), and the energy dispersive X-ray spectroscope (EDX) and electron back-scattering pattern (EBSP) analyses were carried out. Additionally, a micro-area X-ray diffraction analysis (Bluker AXS, D8) was carried out near the weld interface under the condition of $35 \mathrm{kV}$ and $80 \mathrm{~mA}$. The diameter of the collimator was $100 \mu \mathrm{m}$

\section{Results and discussion}

\subsection{Similar joint}

\section{WELD LOBE}

Fig. 2 shows the optimum welding condition range for similar stainless steel joints made by using friction welding under a forging pressure of $150 \mathrm{MPa}$. The joint quality of the weld lobe was estimated by carrying out a bending test. Under the hatched line, the joints fractured at the weld interface during the bending test. While, the joints made under conditions above the hatched line, that is, at a lower threshold, never fractured even where the bending angle was $90^{\circ}$. The upper threshold was defined as the set of welding conditions that led to a burn-off length of more than $2.5 \mathrm{~mm}$ in the present study from a practical standpoint since the welding parameters required to produce a considerable burnoff length was an expensive alternative. Further, in order to obtain strong joints, a high rotation speed was required as the friction time was short. A rotation speed of at least $2000 \mathrm{rpm}$ was required to obtain a high-strength joint. The heat input was

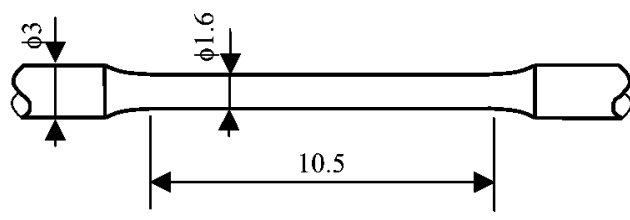

Fig. 1 Dimension of tensile test coupon. (Unit: $\mathrm{mm}$ ) determined by using the rotation speed, friction time, and friction pressure. However, lengthening the friction time did not result in the fabrication of strong joints when the rotation speed was less than the threshold value. Welding at a rotation speed less than the threshold and with a long friction time only increased the burn-off length of the joints and not the joint strength. Consequently, the practical optimum process parameters ranged in the area with a high rotation speed and a short friction time, and a high rotation speed was especially necessary in the case of small-scale friction welding. The lower threshold of rotation speed was the same in the case of both stainless steels. However, since the yield strength of type 430 stainless steel is lower than that of type 304 stainless steel, a larger burn-off length was obtained in type 430 stainless steel than in type 304 stainless steel, resulting in a narrower process window in the case of type 430 stainless steel than that in the case of type 304 stainless steel.

\section{MICROSTRUCTURES}

The optical microstructures of type 304 stainless steel similar joints are shown in Fig. 3. Fig. 4 shows the micro-area XRD patterns near the weld interface of type 304 joints welded at rotation speed of $2000 \mathrm{rpm}$. The weld started forming from the middle of the radius toward the center of the round bars, leaving an unbonded region at the periphery of the weld interface (Fig. 3a), which caused a brittle interfacial fracture during the bending test. In the case when the rotation speed was $2500 \mathrm{rpm}$, the macroscopic defects at the periphery disappeared. However, the oxide films that were detected by the EDX analysis remained at the weld interface (Fig. 3b). This type of joints exhibited
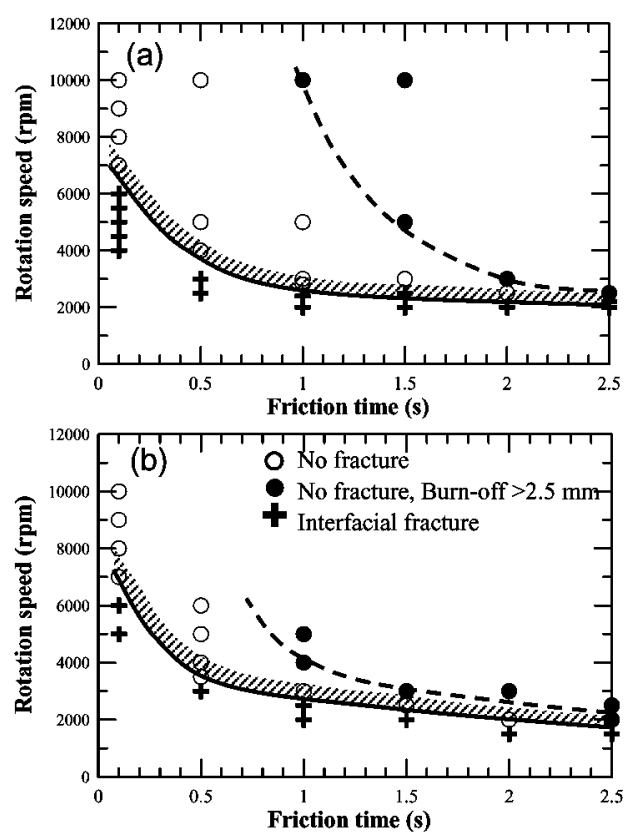

Fig. 2 Weld lobes for similar joints; (a) type 304 and (b) type 430 stainless steels, Joint quality was estimated by the bending test. 
(a)

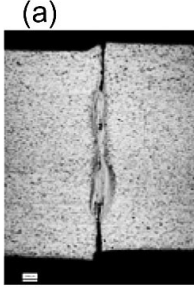

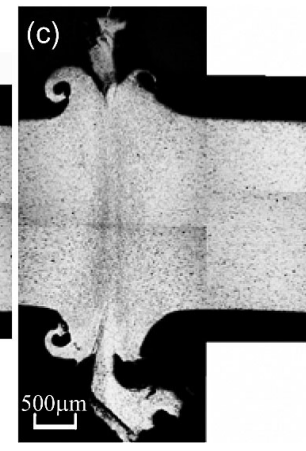

Fig. 3 Cross sections of type 304 stainless steel joints made with various rotation speeds; (a) $2000 \mathrm{rpm}$, (b) $2500 \mathrm{rpm}$ and (c) $5000 \mathrm{rpm}$. The friction time is $1.5 \mathrm{~s}$. Arrows show oxides.

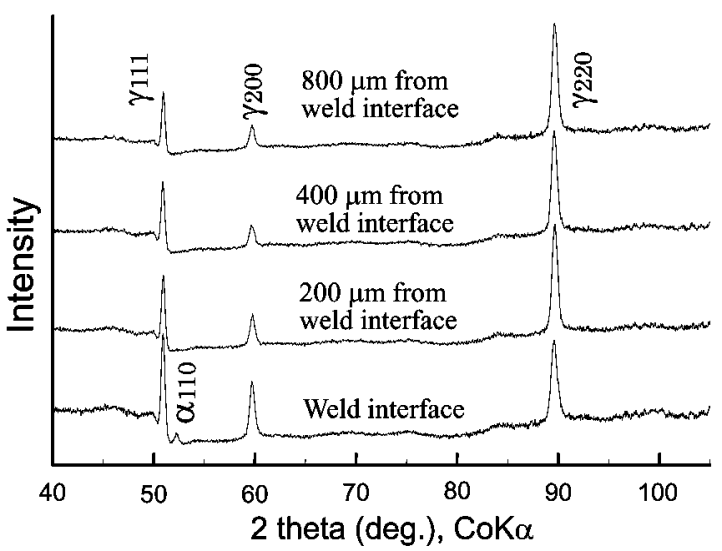

Fig. 4 Micro-area XRD patterns nearby weld interface of type 304 similar joint made with the welding condition of $2000 \mathrm{rpm}$

interfacial fractures with some plastic deformation of base alloys during the bending test. At a higher rotation speed, neither defects nor oxide films were observed at the weld interface, resulting in high joint strength. Microstructural refinement due to the dynamic recrystallization was observed near the weld interface, a phenomenon similar to that in "regular-scale" friction welding ${ }^{9-11)}$. Additionally, a phase transformation was also observed. A small amount of strain-induced martensite was formed at the weld interface of the joint made at a rotation speed of $2000 \mathrm{rpm}$ (Fig. 4). The martensite was not observed when the rotation speed increased. In the case of a low rotation speed, macroscopic deformation was negligible in this joint, as shown in Fig. 3a. A small part of the material near the weld interface was significantly worked at a low temperature, resulting in the formation of martensite.

Fig. 5 shows the cross section of type 430 stainless steel joints welded at various rotation speeds. The peripheral region was not welded, and many oxide films remained at the weld interface in the case when the rotation speed was $3000 \mathrm{rpm}$. The defects and oxide films disappeared with an increase in the rotation speed, which led to the formation of a strong joint. Only an alpha phase was detected near the weld interface under all welding conditions by the micro-area XRD analysis.
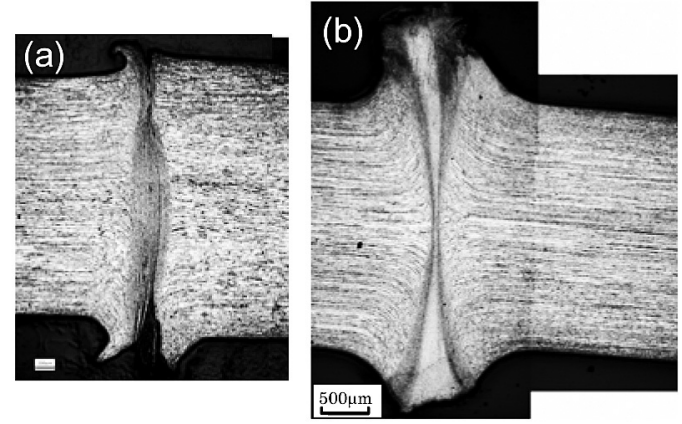

Fig. 5 Cross sections of type 430 stainless steel joints made with various rotation speeds; (a) $3000 \mathrm{rpm}$ and (b) $5000 \mathrm{rpm}$. $\left(\mathrm{t}_{1}=1.0 \mathrm{~s}\right)$

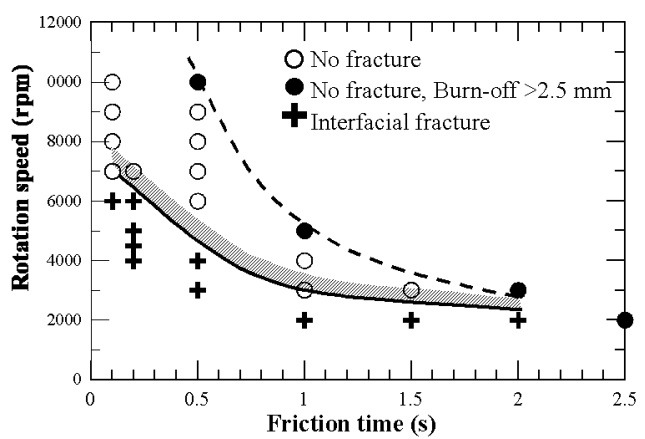

Fig. 6 Weld lobe for dissimilar joint of type 304 to type 430 stainless steels. Joint quality was estimated by simple bond test.

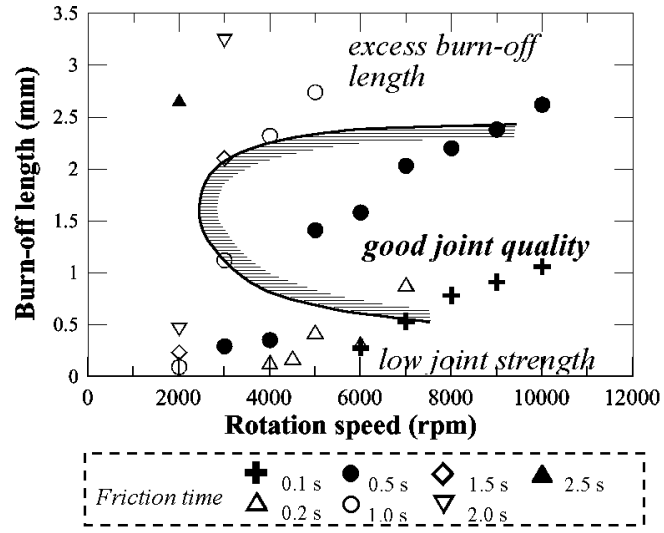

Fig. 7 Effect of friction time and rotation speed on burn-off length. Hatching area shows the practical proccess window, that is to say, high joint strength and adequate bum-off length.

\subsection{Dissimilar joint}

\section{WELD LOBE}

The weld lobe for dissimilar joints between type 304 and 430 stainless steels is shown in Fig. 6. The effect of rotation speed and friction time on the burn-off length of joints is shown in Fig. 7. The overall trend is similar to that of the similar joints, as shown in Fig. 2. The lower threshold of rotation speed required to make a strong joint was $3000 \mathrm{rpm}$. The upper threshold line indicated the intermediate location between two weld lobes of similar welding, as shown in Fig. 2. The burn-off length increased as the rotation speed and the friction time increased. 
A C-curve is given in Fig. 7 from the viewpoint of joint strength and burn-off length. With respect to only the joint strength, a burn-off length of at least $0.5 \mathrm{~mm}$ was required to avoid an interfacial fracture. In general, it is known that the burnoff length is used as one of the indicators to estimate the joint quality ${ }^{12}$, which does not necessarily mean that the burn-off length is the most accurate indicator. Fig. 8 shows an example of a lowstrength joint with a burn-off length of $1.0 \mathrm{~mm}$. The joint was fabricated at a low rotation speed, long friction time, and high forging pressure of $300 \mathrm{MPa}$. The axial displacement occurred because of the high forging pressure at a low temperature, and many oxides were mechanically caught into type 430 stainless steel near the weld interface, resulting in poor joint strength. It is believed that a proper balance of heat and deformation hysteresis is necessary for obtaining strong joints. The lamellar structure of the oxides increased as the friction time increased at a low rotation speed.

\section{MICROSTRUCTURES}

Fig. 9 shows the cross sections and microstructures at the weld interface of the joints welded at different friction times at a rotation speed of $5000 \mathrm{rpm}$ under a forging pressure of $150 \mathrm{MPa}$. Macroscopic deformation was observed only in type 430 stainless steel. The flash increased with an increase in the friction time
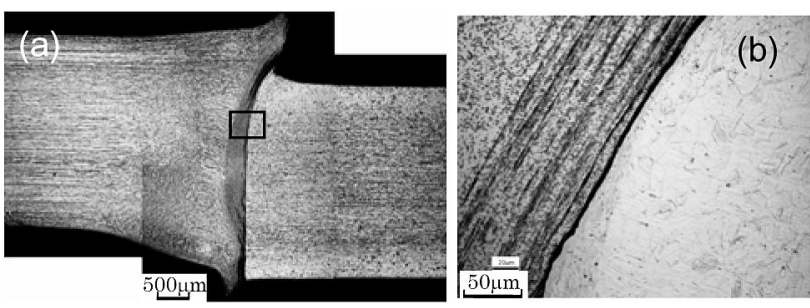

Fig. 8 Cross section (a) and microstructure at the weld interface (b) of friction welded joints made with rotation speed of $2000 \mathrm{rpm}$, friction time of $2.0 \mathrm{~s}$ and forging pressure of $300 \mathrm{MPa}$. Bum-off length of the joint is $1.0 \mathrm{~mm}$. with a corresponding increment in the burn-off length. A considerable number of oxide films remained at the entire weld interface, resulting in the formation of a lamellar structure in type 430 stainless steel (Fig. 9b). It is believed that lamellar oxides consist of not only initial oxide films on the faying surface but also newly formed oxides during the friction process. As the friction time increased, the oxides were squeezed out with the flash and/or dissolved into the matrix, leaving no oxides at the interface. After the oxides were removed, another lamellar structure was observed in type 430 stainless steel near the weld interface (Fig. 9d). The phase mapping done by using the EBSP analysis at the weld interface is shown in Fig. 10. The lamellar structure consisted of alpha and gamma phases. The gamma phase delaminated from type 304 stainless steel was mechanically
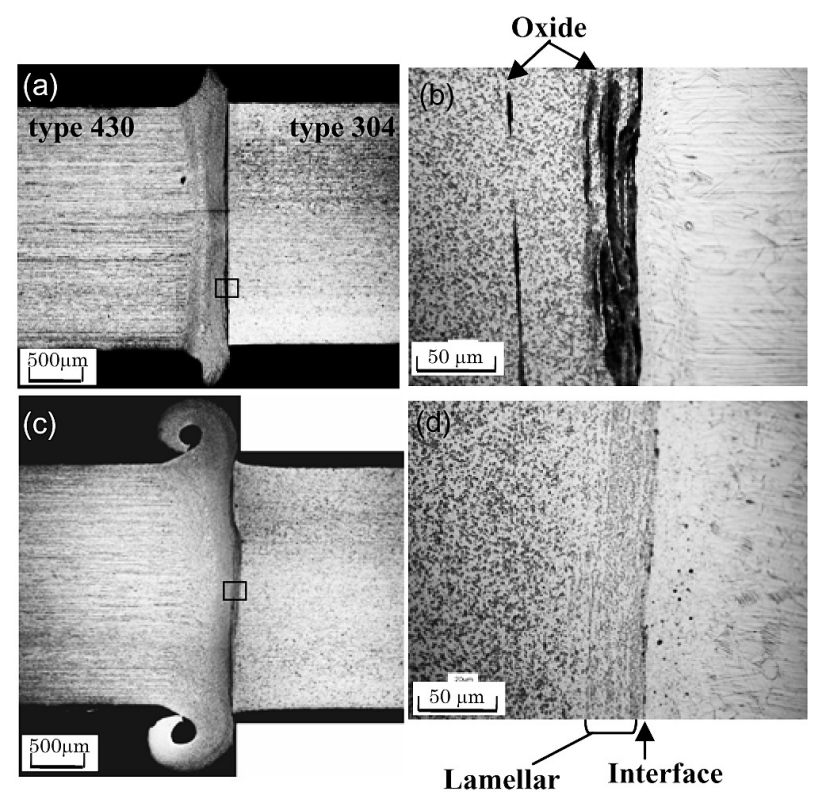

Fig. 9 Cross sections and microstructures at the weld interface of friction welded joints made with different friction times; (a) $0.2 \mathrm{~s}$ and (c) $0.5 \mathrm{~s}$. Images of (b) and (d) show the highlighted areas in (a) and (c), respectively. Rotation speedd is $5000 \mathrm{rpm}$.

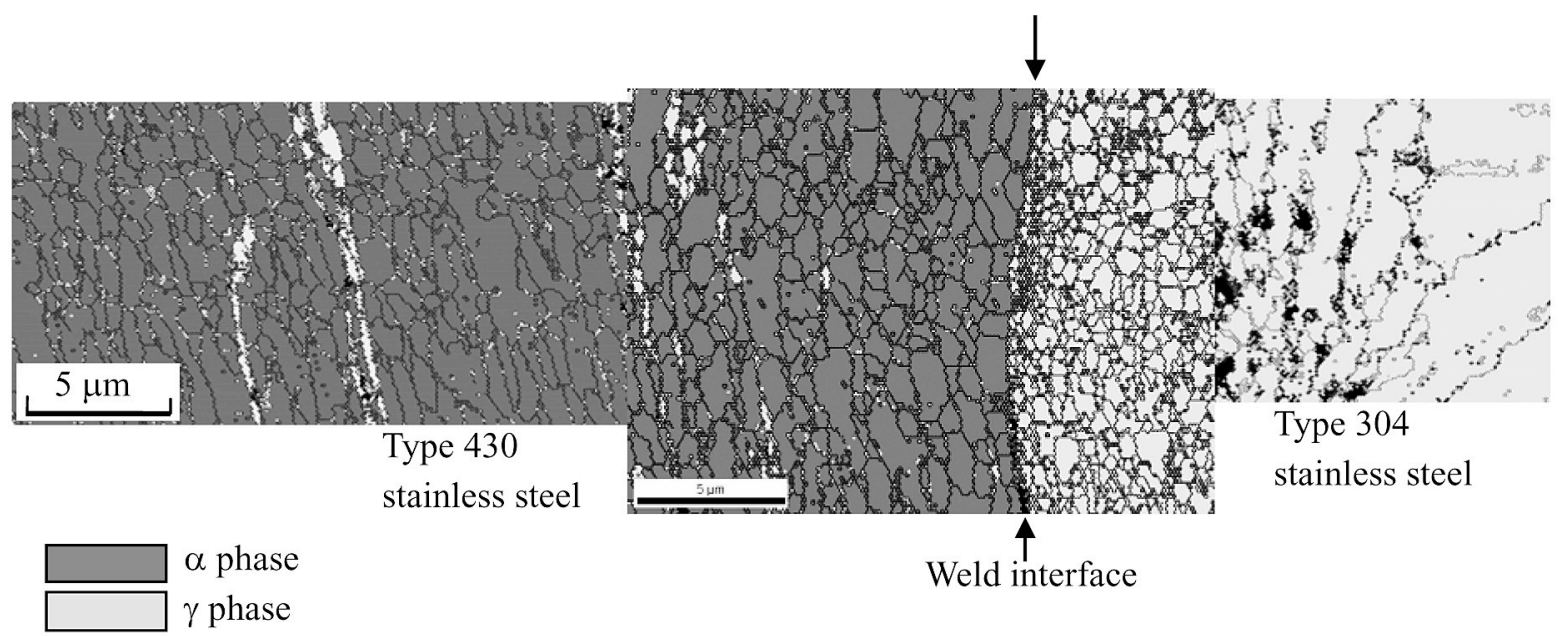

Fig. 10 EBSP phase mapping of alpha and gamma phases near the weld interface. 


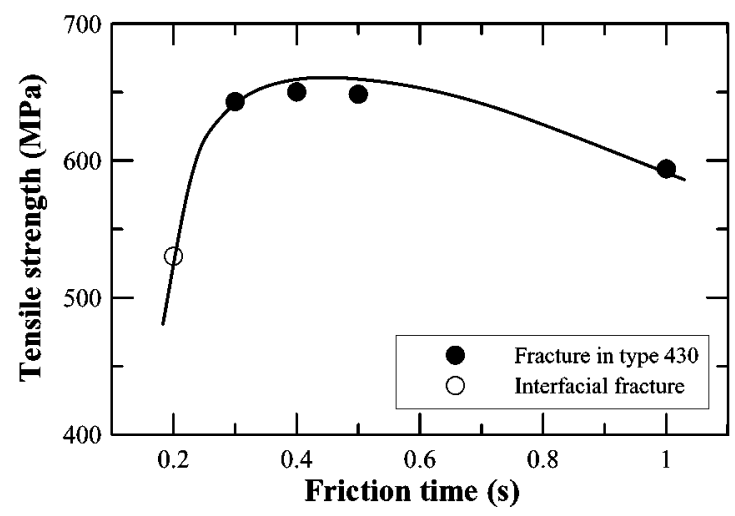

Fig. 11 Effect of friction time on tensile strength of dissimilar joints welded with the rotation speed of $5000 \mathrm{rpm}$.

stacked in type 430 stainless steel by the rotation, resulting in the formation of the lamellar structure. Moreover, a microstructural refinement due to dynamic recrystallization was observed in type 304 steel as well as in type 430 steel. This means that type 304 stainless steel close to the weld interface was locally and strongly worked at the elevated temperature although the macroscopic deformation was not observed. The alpha phase formed in the microstructural refinement region in type 304 might be the straininduced martensite.

\section{TENSILE STRENGTH}

Fig. 11 shows the tensile strength as a function of friction time at the rotation speed of $5000 \mathrm{rpm}$. The tensile strength increased first and subsequently decreased after a further increase in friction time. Corresponding to the change in friction time, the fracture location also changed from at the weld interface to in the HAZ of type 430 base alloy. This characteristic behavior is believed to result from the competition between the improvement of interfacial bonding (determined by both the bonded area and the interfacial strength) and the local softening of steel in the HAZ (resulting from recrystallization). Although the obvious unbonded area was not observed at the weld interface when the friction time was $0.2 \mathrm{~s}$, many stacked oxide layers remained at the interface like Fig. 8b, which led to poor joint strength.

\section{Conclusions}

Small-scale friction welding of stainless steels was investigated by means of mechanical testing and metallurgical examination. The main conclusions include the following:

1. Weld lobes for similar and dissimilar stainless steels joints were exhibited. Small-scale friction welding required a higher rotation speed than regular-scale friction welding. The welding conditions of high rotation speed and short friction time favored small-scale friction welding.

2. Joint strength was determined by the bonded area and the interfacial strength. The existence of oxide layers at the weld interface reduced the interfacial strength. The oxide layers had to be pushed out with a flash. In addition, the excess formation of oxides could be minimized by using a high rotation speed.

3. The burn-off length was an insufficient indicator of the joint quality in itself. Proper balance of heat and deformation hysteresis had to be controlled in order to obtain strong joints.

4. Microstructural refinement occurred near the weld interface in both stainless steels because of dynamic recrystallization. In dissimilar welding, a lamellar structure with alpha and gamma phases was formed in the type 430 steel, while strain-induced martensite was formed in the type 304 steel.

\section{Acknowledgements}

This work was partially supported by the Ministry of Education, Science, Sports and Culture, Grant-in-Aid for Scientific Research (C), 19560737, 2008. This work was performed under the Cooperative Research Program of Institute for Joining and Welding Research Institute, Osaka University. The authors acknowledge Mr. Jin Nishijima, Shinko Electric Co. Ltd., for his valuable advisement.

\section{References}

1) ASM International Handbook Comittee: ASM Handbook, Vol.6, Welding, Brazing, and Soldering, ASM International, Materials Park, OH, (2000), 441

2) J.C. Vilafuerte and H.W. Kerr: Key Engineering Materials Vols.69\&70 (1992), 129

3) V.V. Satyanarayana, G. Madhusudhan Reddy and T. Mohandas: J. Materials Processing Technology, 160 (2005), 128-137.

4) Mumin Sahin: Materials \& Design, 28 (2007), 2244-2250.

5) N. Özdemir: Materials Letters, 59(2005), 2504-2509.

6) C. Pan, L. Hu, Z. Li and T.H. North: J. Materials Science, 31 (1996), 3667-3674

7) A. Hasui: J. Jpn. Weld. Soc., 32 (1963), 763-769. (Japanese)

8) K.G.K Murti and S. Sundaresan: Mater. Sci. Technol., 2 (1986), 865-870.

9) I. Masumoto and H. Hira: J. Jpn. Weld. Soc., 48 (1979), 926-931. (Japanese)

10) S. Fukumoto, H. Tsubakino, M. Aritoshi, T. Tomita and K. Okita: Mater. Sci. Technol., 18 (2002), 219-225.

11) S. Fukumoto, S. Tanaka, T. Ono, H. Tsubakino, T. Tomita, M Aritoshi and K. Okita: Mater. Trans., 47 (2006), 1071-1076.

12) T.H. Hazlett and K.K. Gupta: Weld. Res. Suppl., November, (1963), 490s-494s. 